\title{
Período de formação do cacho e biorreguladores na produção e qualidade da banana 'Grande Naine'
}

\author{
Period of bunch formation and growth regulators \\ on yield and quality of banana 'Grande Naine' \\ Juliana Domingues Lima ${ }^{I^{*}}$ Jéssica Santa Rosa ${ }^{\mathrm{I}}$ \\ Wilson da Silva Moraes ${ }^{I I}$ Silvia Helena Modenese-Gorla da Silva ${ }^{I}$ \\ Danilo Eduardo Rozane ${ }^{I}$ Eduardo Nardini Gomes ${ }^{I}$
}

\section{- NOTA -}

\section{RESUMO}

Objetivou-se determinar o efeito do período de formação do cacho e dos biorreguladores na produção e qualidade da banana 'Grande Naine'. O experimento foi realizado em delineamento inteiramente casualizado em parcelas subdivididas, com seis repetições. Consideram-se, nas parcelas, os periodos de formação do cacho, verão e outono, e nas subparcelas, os biorreguladores: duas aplicações com água, giberelina $\left(A G_{3}\right.$, $\left.200 m g L^{-1}\right)$, auxina $\left(2,4 \mathrm{D} ; 10 \mathrm{mg} \mathrm{L}^{-1}\right)$, citocinina (TDZ, $\left.150 \mathrm{mg} \mathrm{L}^{-1}\right)$ e a mistura de giberelina, auxina e citocinina $\left(A G_{3}, 56,3 m g L^{-1}\right.$, AIB, 56,3mg $L^{-1}$ e ZEA, 101,3mg $L^{-1}$ ). Os periodos de formação do cacho influenciam o número de pencas, o tamanho, a vida póscolheita, o pH, a acidez titulável, a razão sólidos solúveis e acidez titulável e a firmeza do fruto. A mistura de biorreguladores eleva o peso do cacho e da $4^{a}$ penca em cachos formados no verão.

Palavras-chave: Musa spp., auxina, citocinina, giberelina, relação fonte/dreno.

\section{ABSTRACT}

The objectives of this study were to determine the effect of climatic conditions during the period of bunch formation and growth regulators on yield and quality of banana 'Grande Naine'. The experiment was conducted in a completely randomized split plot with six replications. It was considered the plots, and the periods of bunch formation, summer and autumn. In the subplots it was considered the growth regulators: two applications were made with water, gibberellin $\left(G A_{3}, 200 \mathrm{mg} \mathrm{L}^{-1}\right)$, auxin $(2.4-D, 10 \mathrm{mg}$ $\left.L^{-1}\right)$, cytokinin (TDZ, 150mg $\left.L^{-1}\right)$ and a mixture of gibberellin, auxin and cytokinin $\left(A G_{3}, 56.3 \mathrm{mg} \mathrm{L}^{-1} ; A I B, 56.3 \mathrm{mg} \mathrm{L}^{-1}\right.$ and $Z E A$, $\left.101.3 \mathrm{mg} \mathrm{L}^{-1}\right)$. Periods of bunch formation influence the number of hands, the size, shelf life, $p H$, titratable acidity, soluble solids and titratable acidity ratio and the firmness of the fruit. The mixture of growth regulators increase the weight of the bunch and the 4th hand bunches formed in the summer.

Key words: Musa spp., auxin, cytokinin, gibberellins, source-sink relationship.
$\mathrm{Na}$ bananeira, há uma variação no peso dos frutos em função da posição que este ocupa no cacho. Pencas localizadas na porção proximal, que se diferenciam primeiro, contêm frutos 30-40\% maiores do que da porção distal do cacho (JULLIEN et al., 2001). O gradiente negativo de peso e tamanho dos frutos é prejudicial para comercialização, pois o cacho é colhido inteiro. O peso do fruto está relacionado com o número de células ao longo do raio (JULLIEN et al., 2001) e a competição por fotoassimilados entre pencas de diferentes posições limita a divisão celular. Um dos modos de reduzir a variação de tamanho é melhorar a força do dreno com o uso de biorreguladores, promovendo $\mathrm{o}$ incremento na capacidade de crescimento do fruto. Assim, objetivou-se avaliar a influência do período de formação do cacho e biorreguladores na produção e qualidade da banana 'Grande Naine' (AAA).

$\mathrm{O}$ experimento foi realizado em Registro,

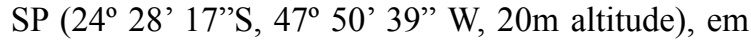
delineamento inteiramente casualizado em parcelas subdivididas, com seis repetições. Consideraramse, nas parcelas, os períodos de formação do cacho, verão e outono, e, nas subparcelas, os biorreguladores aplicados após o início da frutificação: duas aplicações com água, giberelina (200mg $\mathrm{L}^{-1} \mathrm{de} \mathrm{AG}_{3}$ ), auxina (10 $\mathrm{mg} \mathrm{L}^{-1}$ de 2,4 D), citocinina (150 $\mathrm{mg} \mathrm{L}^{-1}$ de TDZ) e mistura de giberelina, auxina e citocinina $(56,25 \mathrm{mg}$ $\mathrm{L}^{-1}$ de $\mathrm{AG}_{3}, 56,25 \mathrm{mg} \mathrm{L}^{-1}$ de AIB e $101,25 \mathrm{mg} \mathrm{L}^{-1}$ de ZEA), exceto para o peso da penca, número de frutos por penca e diâmetro do fruto, em que foi adotado o

\footnotetext{
'Campus Experimental de Registro, Universidade Estadual Paulista “Júlio de Mesquita Filho" (UNESP), Rua Nélson Brihi Badur, 430, Vila Tupy, 11900-000, Registro, SP, Brasil. E-mail: judlima@registro.unesp.br. *Autor para correspondência.

IIAgência Paulista de Tecnologia dos Agronegócios (APTA), Regional Vale do Ribeira, Registro, SP, Brasil. Recebido 23.04.14 Aprovado 13.01.15 Devolvido pelo autor 09.04.15 CR-2014-0622.R1
} 
delineamento experimental casualizado em parcelas subdivididas no tempo, em esquema fatorial $5 \times 3$ (cinco biorreguladores e três posições das pencas no cacho) e seis repetições. Utilizaram-se como fonte de giberelina, Progibb ${ }^{\circledR}$; de auxina, DMA $806 \mathrm{BR}^{\circledR}$; de citocinina, Dopp Ultra $\mathrm{SC}^{\circledR}$; e da mistura, Stimulate ${ }^{\circledR}$. A primeira pulverização foi feita em $06 / 03 / 12$ no verão, e em 15/06/12 no outono, e a segunda, 30 dias após a primeira, aplicando-se $120 \mathrm{~mL}$ de calda cacho ${ }^{-1}$ com $0,1 \%$ de Tween 20 .

A colheita foi realizada quando os frutos da última penca atingiram $30 \mathrm{~mm}$ de diâmetro, quando foi determinado o número de pencas, peso do cacho, e de três pencas, a primeira, a última e a $4^{\text {a }}$ penca a partir da porção proximal do cacho e, nestas, o número, o diâmetro e o comprimento dos frutos. Avaliou-se apenas o efeito do período de formação do cacho nas variáveis número de pencas e número de frutos por penca, visto que são definidas na diferenciação floral. A 4⿳亠丷a penca foi armazenada a $25^{\circ} \mathrm{C}$ até os frutos apresentarem casca amarela, estádio 6 da escala de Von LOESECKE (1950), submetida às avaliações: a) vida pós-colheita, número de dias entre a colheita e maturação; b) perda de peso; c) firmeza, em penetrômetro; d) pH; e) sólidos solúveis; f) acidez titulável (AOAC, 1997); g) SSAT, razão sólidos solúveis e acidez titulável; h) cor da casca com colorímetro, no sistema CIELab, em que L é a luminosidade, a, o vermelho/verde e b, o amarelo/ azul. Foram coletados dados climáticos e calculada a soma térmica usando $14^{\circ} \mathrm{C}$ como base (GANRY \& MEYER, 1975). Os dados foram submetidos à análise de variância e as médias comparadas pelo teste Tukey.
No verão, os cachos exibiram maior quantidade de pencas que no outono (Tabela 1). O número de frutos na $1^{\mathrm{a}}$ penca, o comprimento e o diâmetro do fruto na $4^{\mathrm{a}}$ penca e o diâmetro do fruto na última penca também foram maiores no verão que no outono. Ao contrário, o peso e o número de frutos da última penca foram mais baixos no verão que no outono.

A radiação global acumulada na formação do cacho foi a mesma, $1512 \mathrm{MJ} \mathrm{m}^{-2}$ no verão e $1566 \mathrm{MJ} \mathrm{m}^{-2}$ no outono, o que contribuiu para não haver diferença no tempo para colheita, que foi em média de 145 dias. Todavia, no verão, a precipitação acumulada foi mais elevada $(790 \mathrm{~mm})$, assim como as temperaturas médias máxima $\left(25,40^{\circ} \mathrm{C}\right)$ e mínima $\left(16,14^{\circ} \mathrm{C}\right) \mathrm{em}$, pelo menos $1{ }^{\circ} \mathrm{C}$, o que resultou em uma soma térmica mais alta (1068 graus-dias) e umidade relativa média do ar mais baixa (66\%). No outono, a precipitação acumulada $593 \mathrm{~mm}$, a temperatura média máxima, $24,14^{\circ} \mathrm{C}$, a média mínima, $14,14^{\circ} \mathrm{C}$, a soma térmica, 812 graus-dias e a umidade relativa média, $81 \%$. BUGAUD et al. (2009) também observaram a necessidade de radiação total entre 1370 a $1940 \mathrm{MJ}$ $\mathrm{m}^{-2}$ para colheita de frutos da mesma variedade em diferentes épocas e regiões, no entanto, a soma térmica atingida foi de 950 a 1135 graus-dia, faixa que não inclui a soma térmica verificada no outono.

Provavelmente, não houve limitação da fotossíntese pela disponibilidade de água, isto porque cachos colhidos nos dois períodos não diferiram quanto ao peso, demandaram o mesmo tempo e radiação para enchimento dos frutos. $\mathrm{Na}$ primeira fase de formação do fruto, predomina a divisão celular, que define o número total de células

Tabela 1 - Número de pencas no cacho (NPC), número de frutos na penca 1 (NFP1), comprimento do fruto na penca 4 (CFP4), diâmetro do fruto na penca 4 (DFP4), peso da última penca (PUP), vida pós-colheita (VPC), pH, acidez titulável (AT), razão sólidos solúveis e acidez titulável (SSAT) e firmeza (FIRM) de frutos da bananeira 'Grande Naine', formados no verão e outono. Registro, 2012.

\begin{tabular}{|c|c|c|c|c|c|}
\hline & $\mathrm{NPC}$ & NFP1 & $\mathrm{CFP} 4 \mathrm{~cm}$ & DFP4 $\mathrm{cm}$ & PUP Kg \\
\hline Verão & $9,88 \mathrm{~A}$ & $27,92 \mathrm{~A}$ & $26,03 \mathrm{~A}$ & $34,81 \mathrm{~A}$ & $1,84 \mathrm{~B}$ \\
\hline Outono & $8,90 \mathrm{~B}$ & $24,60 \mathrm{~B}$ & $24,33 \mathrm{~B}$ & $32,92 \mathrm{~B}$ & $2,00 \mathrm{~A}$ \\
\hline Média & 9,34 & 26,11 & 25,10 & 33,84 & 1,93 \\
\hline cv1 $(\%)$ & 10,46 & 17,43 & 7,86 & 53,92 & 5,19 \\
\hline \multirow[t]{2}{*}{$\operatorname{cv} 2(\%)$} & 0,99 & 21,00 & 7,26 & 53,40 & 4,89 \\
\hline & VPC dias & $\mathrm{pH}$ & AT g ác málico $100 \mathrm{~g}^{-1}$ & STAT & FIRM N \\
\hline Verão & $12,57 \mathrm{~B}$ & $5,23 \mathrm{~A}$ & $0,20 \mathrm{~B}$ & $75,28 \mathrm{~A}$ & $13,49 \mathrm{~A}$ \\
\hline Outono & $20,57 \mathrm{~A}$ & $5,00 \mathrm{~B}$ & $0,25 \mathrm{~A}$ & $62,01 \mathrm{~B}$ & $11,17 \mathrm{~B}$ \\
\hline Média & 16,64 & 5,12 & 0,22 & 68,17 & 12,25 \\
\hline $\operatorname{cv1}(\%)$ & 16,23 & 3,16 & 11,00 & 13,16 & 15,42 \\
\hline $\operatorname{cv} 2(\%)$ & 14,26 & 2,67 & 10,97 & 12,80 & 13,90 \\
\hline
\end{tabular}

Médias seguidas da mesma letra, maiúscula na coluna e minúscula na linha, não diferem entre si, a 5\% de probabilidade pelo teste de Tukey. $\mathrm{CV}_{1}$ - subparcela; $\mathrm{CV}_{2}$ - parcela. 
da polpa e seu peso final (JULLIEN et al., 2001). O aumento da temperatura do ar nesta fase, até certo limite, aumenta a taxa de divisão celular (JULLIEN et al., 2001), o que pode originar frutos maiores, tal como no verão em relação ao outono (Tabela 1 ). Considerando que cachos colhidos nos dois períodos não diferiram quanto ao peso, o maior número de frutos na $1^{\mathrm{a}}$ penca, maior diâmetro e comprimento do fruto na $4^{\mathrm{a}}$ penca, no verão, deveria ser compensado pela redução do peso ou tamanho nas últimas pencas, o que concorda com o menor peso da última penca e demonstra que as condições climáticas modificaram apenas a distribuição de fotoassimilados.

Houve interação entre período de formação do cacho e biorregulador para peso do cacho, peso da $4^{\mathrm{a}}$ penca, coordenada de cromaticidade $b$ da cor da casca e firmeza da polpa (Tabela 2). No verão, a mistura resultou em maior peso do cacho, comparada aos biorreguladores administrados isoladamente, contudo, no outono, esta resposta não se repetiu. Esses resultados indicam efeito dos biorreguladores no enchimento do fruto (peso da $4^{\text {a }}$ penca), com resposta dependente do período de formação do cacho. A aplicação de citocinina aumentou o peso do cacho no outono, comparado ao verão, enquanto a aplicação da mistura de biorreguladores favoreceu o peso do cacho no verão, comparativamente ao outono. Apesar de a giberelina, quando aplicada isolada, não ter alterado o peso ou tamanho do fruto, SAMRA et al. (1989) e EBEED et al. (2008) observaram elevação dessas variáveis.

O peso das pencas, o número e o diâmetro dos frutos decresceu ao longo do cacho, devido à influência da posição, o que justifica a prática da remoção das últimas pencas para incremento das remanescentes. Quando se compara a $1^{\mathrm{a}}$ com a $4^{\mathrm{a}}$ penca e a 4⿳亠口冋 com a última penca, a redução no diâmetro do fruto foi pequena, respectivamente, de $0,04 \mathrm{~mm}$ $(0,12 \%)$ e $2,31 \mathrm{~mm}(7 \%)$, já a redução no peso, mais alta, $1,40 \mathrm{~kg}(31 \%)$ e $1,32 \mathrm{~kg}(42 \%)$, concordando com JULLIEN et al. (2001). O número de frutos na 1ํ. penca foi mais elevado no verão ( 28 frutos), que no outono ( 25 frutos). No entanto, entre a $4^{\mathrm{a}}$ e última penca, não houve diferença no número de frutos entre períodos. Em média, a variação no número de frutos entre $1^{\text {a }}$ e $4^{\mathrm{a}}$ penca e $4^{\mathrm{a}}$ e última penca foi de 8 frutos $(30 \%)$ e 3 frutos $(15 \%)$, respectivamente.

Tabela 2 - Peso do cacho (PC), peso da $4^{\mathrm{a}}$ penca (P4P), coordenada de cromaticidade $b$ da cor da casca (Coord b) e firmeza da polpa (F) de frutos de bananeira 'Grande Naine', com período de formação do cacho verão e outono, submetidos a aplicações de reguladores de crescimento no início da frutificação. Registro, 2012.

\begin{tabular}{|c|c|c|c|c|}
\hline & Verão & Outono & Verão & Outono \\
\hline Água & $32,40 \mathrm{~B} \quad \mathrm{a}$ & $31,13 \mathrm{~A} \mathrm{a}$ & $2,90 \mathrm{~B} \quad \mathrm{a}$ & $3,32 \mathrm{~A} \mathrm{a}$ \\
\hline Giberelina & $30,95 \mathrm{~B}$ a & $29,57 \mathrm{~A} \mathrm{a}$ & $3,00 \mathrm{AB}$ a & $3,00 \mathrm{~A} \mathrm{a}$ \\
\hline Auxina & $31,72 \mathrm{~B}$ a & $32,47 \mathrm{~A} \mathrm{a}$ & $3,00 \mathrm{AB}$ a & $3,33 \mathrm{~A} \mathrm{a}$ \\
\hline Citocinina & $27,89 \mathrm{~B} \quad \mathrm{~b}$ & $35,41 \mathrm{~A} \mathrm{a}$ & $3,00 \mathrm{AB}$ a & $3,50 \mathrm{~A} \mathrm{a}$ \\
\hline Mistura & $39,28 \mathrm{~A}$ a & $29,85 \mathrm{~A} \mathrm{~b}$ & $3,80 \mathrm{~A} \quad \mathrm{a}$ & $3,33 \mathrm{~A} \mathrm{a}$ \\
\hline Média & $32,40 \mathrm{a}$ & $31,13 \mathrm{a}$ & $3,14 \mathrm{a}$ & $3,30 \mathrm{a}$ \\
\hline Média & \multicolumn{2}{|c|}{32,02} & \multicolumn{2}{|c|}{3,23} \\
\hline $\mathrm{CV}_{1}(\%)$ & \multicolumn{2}{|c|}{14,94} & \multicolumn{2}{|c|}{17,41} \\
\hline \multirow[t]{2}{*}{$\mathrm{CV}_{2}(\%)$} & \multicolumn{2}{|c|}{9,74} & \multicolumn{2}{|c|}{3,23} \\
\hline & Verão & Outono & Verão & F $(\mathrm{N})$ - \\
\hline Água & $45,94 \mathrm{BC} \quad \mathrm{a}$ & $50,48 \mathrm{~A} \mathrm{a}$ & $10,04 \mathrm{~B}$ & $10,85 \mathrm{~A}$ \\
\hline Giberelina & $48,96 \mathrm{ABC}$ a & $53,30 \mathrm{~A} \mathrm{a}$ & $14,89 \mathrm{AB}$ & $13,19 \mathrm{~A}$ \\
\hline Auxina & $42,94 \mathrm{C} \quad \mathrm{b}$ & $54,09 \mathrm{~A} \mathrm{a}$ & $19,01 \mathrm{~A}$ & $10,25 \mathrm{~A}$ \\
\hline Citocinina & $52,19 \mathrm{AB}$ a & $50,58 \mathrm{~A} \mathrm{a}$ & $12,63 \mathrm{~B}$ & $9,61 \mathrm{~A}$ \\
\hline Mistura & $59,20 \mathrm{~A} \quad \mathrm{a}$ & $56,05 \mathrm{~A} \mathrm{~b}$ & $12,01 \mathrm{~B}$ & $11,97 \mathrm{~A}$ \\
\hline Média & $49,97 \mathrm{~b}$ & $52,90 \mathrm{a}$ & $13,49 \mathrm{a}$ & $11,17 \mathrm{~b}$ \\
\hline Média & \multicolumn{2}{|c|}{51,54} & \multicolumn{2}{|c|}{12,25} \\
\hline $\mathrm{CV}_{1}(\%)$ & \multicolumn{2}{|c|}{9,30} & \multicolumn{2}{|c|}{15,42} \\
\hline $\mathrm{CV}_{2}(\%)$ & \multicolumn{2}{|c|}{8,73} & \multicolumn{2}{|c|}{13,90} \\
\hline
\end{tabular}

Médias seguidas da mesma letra, maiúscula na coluna e minúscula na linha, não diferem entre si, a 5\% de probabilidade pelo teste de Tukey. $\mathrm{CV}_{1}$ - subparcela; $\mathrm{CV}_{2}$ - parcela. 
Os fatores testados não influenciaram a perda de peso, a coordenada de cromaticidade $a$ da cor da casca e o teor de sólidos solúveis, com médias de $12 \%, 0,85$ e $15^{\circ}$ Brix, respectivamente. Todavia, a vida pós-colheita de frutos foi menor no verão do que no outono, assim como a acidez titulável (Tabela 1). Ao contrário, o pH e a razão SSAT no verão foram mais elevados no verão que no outono. Diferenças na firmeza da polpa, decorrentes da aplicação de biorreguladores, só foram detectadas no verão, sendo mais elevada em frutos tratados com auxina, seguido de giberelina e por último com água, citocinina e mistura, que não diferiram entre si (Tabela 2). Diferença entre períodos ocorreu apenas para frutos tratados com auxina, que tiveram firmeza no verão superior ao outono.

Auxina aplicada no verão reduziu a luminosidade da casca dos frutos. Auxina no verão tornou a casca menos amarela (menores valores da coordenada b), do que no outono (Tabela 1). No verão, frutos menos amarelos foram os que receberam auxina e os mais amarelos, os tratados com a mistura de reguladores de crescimento, enquanto, no outono, não houve diferenças entre os tratamentos.

Conclui-se que os períodos de formação do cacho, verão e outono, influenciam o número de pencas, o tamanho, a vida pós-colheita, o $\mathrm{pH}$, a acidez titulável, a razão sólidos solúveis e acidez titulável e a firmeza do fruto. A mistura auxina, citocinina e giberelina eleva o peso do cacho e da $4^{\mathrm{a}}$ penca em cachos formados em inflorescências emitidas no verão.

\section{AGRADECIMENTOS}

À Fundação de Amparo À Pesquisa do Estado de São Paulo (FAPESP), pela concessão de bolsa à segunda autora
(2012/16614-5), ao Sr. José de Paula Teixeira, pela cessão da área experimental e ao Sr. José Alberto dos Santos, pelo apoio técnico.

\section{REFERÊNCIAS}

ASSOCIATION OF OFFICIAL AGRICULTURAL CHEMISTS (AOAC). Official methods of analysis of the Association of the Agricultural Chemists. 12.ed. Washington, 1997. 1018p.

BUGAUD, C. et al. Relative importance of location and period of banana bunch growth in carbohydrate content and mineral composition of fruit. Fruits, v.64, n.2, p.63-74, 2009. Disponível em: $<$ http://journals.cambridge.org/action/displayFulltext?type $=1$ $\&$ fid $=8083110 \&$ jid $=$ FRU \& volumeId $=64 \&$ issueId $=02 \&$ aid $=8083$ $108 \&$ bodyId $=\&$ membershipNumber $=\&$ societyETOCSession $=>$. Acesso em: 03 fev. 2013. doi: 10.1051/fruits/2009001.

EBEED, S. et al. Effect of gibberelic acid and male bud removal no yield and fruit quality of banana plants. Research Journal of Agriculture and Biological Sciences, v.4, n.4, p.289292, 2008. Disponível em: <http://www.aensiweb.com/rjabs/ rjabs/2008/289-292.pdf>. Acesso em: 03 fev. 2013.

GANRY, J.; MEYER, J.P. Recherche d'une loi d'action de la tempe'rature sur la croissance des fruits du bananier. Fruits, v.30, n.6, p.375-392, 1975.

JULLIEN, A.et al. Effect of pulp cell number and assimilate availability on dry matter accumulation rate in a banana fruit [Musa sp. AAA group 'Grande Naine' (Cavendish subgroup)]. Annals of Botany, v.88, n.2, p.321-330, 2001b. Disponível em: $<$ http://aob.oxfordjournals.org/content/88/2/321.full.pdf + html $>$. Acesso em: 03 fev. 2013. doi: 10.1006/anbo.2001.1464.

SAMRA, N.R. et al. Effect of male bud removal and GA treatments on yield and fruit quality of banana fruits. Journal Agriculture Science Mansoura University, v.14, n.2, p.1206-1213, 1989.

VON LOESECKE, H.W. Bananas. 2.ed. New York: Interscience, 1950. 189p. 